\title{
Intercultural Communication of Chinese Martial Arts in Africa
}

\author{
Taling Tene Rodrigue $^{1^{*}}$ Zhang Yong ${ }^{2}$ Lei Wen ${ }^{3}$ \\ 1. Cameroon, PhD, Research Fellow, Secretary General of Center for African Film \& TV, Institute of \\ African Studies, Zhejiang Normal University. 688 Yingbin avenue, Wucheng district, Jinhua city, \\ Zhejiang province, China. Zip. 321004.
}

2. China, $\mathrm{PhD}$, Associate professor, Director of Center for African Film \& TV, Institute of African Studies, Zhejiang Normal University.

3. China, PhD, Secretary General of Chinese Center for African Anthropological Studies, Institute of African Studies, Zhejiang Normal University.

\begin{abstract}
Intercultural communication is an interpretive context in which people from different cultures create and share meanings. It's an adaptative process in which different cultures interact and co-develop. The Martial arts as inalienable part of humans' culture have played in human history a decisive role in connecting people. The 1970's Kungfu movies had introduced the Chinese martial arts to the world, and the establishment of diplomatic relation between the New China and different countries of the world have speed up the global communication of the Chinese martial arts, opening a new window to understand the Chinese people. However, in the African continent, the Chinese martial arts' communication has been unilateral and influenced by many factors such as the communication carrier, the language barrier, the receiver's cultural background, etc., resulting in the "onesided" and "biased" understanding of the Chinese martial culture. In general, the lack of the receiver's perspective in the global communication of Chinese culture has become an obstacle to its internationalization. In fact, in their dissemination processes on the African continent, not only the Chinese martial arts have absorbed many ingredients of local cultures, but have confronted the cultural background and religious beliefs of the local people. The trinity made of "Combat+Dance+Spirituality" that are core constituencies of the African martial arts culture have provided the cultural foundation on which African practitioners have based their interpretation of the Chinese martial arts, thus creating a "cultural gap" between the knowledge package embodied in the Chinese martial arts and referred by the Chinese people as "Chinese Wushu", and the "new-understanding" than has gone from movies to body practices experienced by African people and labeled as "Chinese Kungfu". The communication routes, the receiver's perspective as well as the interaction and co-development of the Chinese martial arts with local cultures in Africa are the main issues explored in this article. The present study is grounded on several months fields works in Africa.
\end{abstract}

Key Words: intercultural communication, cultural gap, Chinese Kungfu, African martial arts

DOI: $10.7176 / \mathrm{NMMC} / 84-06$

Publication date:October $31^{\text {st }} 2019$

\section{Introduction}

The concept of globalization can be understood as the transition from the primitive state of isolation that has separated humanity, nations and states to a global society (Hart 2005). The 21st century is now in the wave of globalization with the rapid development of ICT (Information and Communication Technology), transportation, etc. which not only have speed up communication and exchanges between people, but also have led to a constant and more frequent collision of cultures and civilizations. However, human as a sociocultural animal is conditioned by his social, cultural and historical background when understanding his fellow human. Therefore, in the process of communication and collision between different cultures, misunderstandings are inevitable. Philosophers such as Heidegger, Gadamer, Taylor...labelled that phenomenon as "Pre-understandings" or "Pre-conceptions" (Francisco 2006). They argued that in the process of understanding a new culture, tradition, or civilization, our main concern is "what we can draw out of that culture, tradition or civilization", and that "we cannot fully understand others given the obstruction created by our own cultural, historical and environmental background and conditions". In a word, we interpret others based on our own "pre-understandings", and thus creating a wrong understanding or more technically, a "new-understanding" of others. The Chinese culture on its process of going global has to follow this philosophical principle. In fact, since the 1970s and 1980s, The Chinese martial arts culture has mainly used the film media to communicate in Africa, and more precisely Kungfu movies. The Chinese Kungfu as known from most of those movies is a "marvelous set of skills and hidden knowledge" where practitioners with "high moral virtue" could acquire "flying skills", could fight "hundreds of opponents at once", etc. This is a "bias" understanding of the Chinese martial arts culture, unfortunately propagated by the misused of the film media technology. On the other side, the unawareness of the receivers" cultural background and needs by the communicator have widen the "gap" between the 
information transmitted and the one actually received, which further hinders the intercultural communication purposes. The African martial arts have a long-standing development history. It is a unique cultural process that have shaped the African body's techniques throughout African people's way of living (Taling 2018). The African martial arts are beyond doubt, the main cultural element that have influenced the African receivers' understanding of Chinese martial arts. How to blend in, adapt and co-develop with different cultures are the basic challenges that the Chinese martial arts must overcome in its process of cross-cultural communication with new cultures. Nowadays, the Chinese government has put forward initiatives such as "One Belt and One Road" to communicate with the world and accelerate the development of third-world countries, displaying a firm will to build a new platform for exchanges and cooperation. Even though China and Africa cultural exchanges are traced back thousands of years ago (Taling \& Yao 2017), the present days need of mutual understanding between the people of China and Africa have reached unprecedented highs. The Chinese martial arts' communication in Africa represents one aspect of the overall package of cultural exchanges between China and Africa. However, most discourses on intercultural communication between China and Africa still lack the African perspective, and the question of integration and harmonious coexistence between the Chinese and local African culture is often omitted. To some extent, the needs of African people in these cultural communication processes are frequently ignored and their understanding has remained silent, which are important factors to balance the cultural exchanges, deepen the mutual understanding and promote the win-win cooperation between China and Africa.

\section{2- Short Background History of Chinese Martial Arts Communication in Africa}

The Chinese martial arts have spread into the continent of Africa through two main routes: the films (mainly the Chinese Kungfu movies) and the people-to-people exchanges (after the establishment of diplomatic relationship between China and respective African countries).

\subsection{Chinese Martial Arts Communication in Africa through Kungfu Movies}

The China-Africa film and television exchanges began in 1957, with film exchanges at the front-line (Zhang Yong 2016), and the popularity of Kungfu Movies began with the emergence of Bruce lee. As far as Africa is concerned, the communication of Chinese Kungfu in Africa through Kungfu Movies can be divided into four main stages, each of which is dominated by the most influential Kungfu superstar of its time, namely, the Bruce Lee stage, the Jackie Chan stage, the Jet Li stage and the Donny Yen stage.

\subsubsection{The Bruce Lee Stage}

In the early 1970's, Bruce Lee's four and half Kungfu movies <The Big Boss(1971)>, <Fist of fury(1972)>, $<$ The Way of the Dragon(1972)>, <Enter the Dragon(1973) $>$ and $<$ The Game of Death(1978) $>$ blew a whirlwind of "Kungfu" on the African continent. Among them, the three first movies of his career made in Hong-Kong successfully shaped Bruce's image as a Kungfu star and great master of Chinese Kungfu, and thus starts up the process of Chinese Kungfu' internationalization. On the basis of these 3 movies, Bruce opened Hollywood's gate and sign as the first Chinese actor in history to enter the most influential movie platform in the World. He projected himself as an established superstar with his first and last Hollywood success $<$ Enter the Dragon (1973)>, and from then on fully connected with the world audience including the African one which at that time was in its majority used to traditional western films of cowboys, guns and horses. According to some sources, Bruce lee's films topped the box office in Senegal in 1975 (David Sembene 2001).
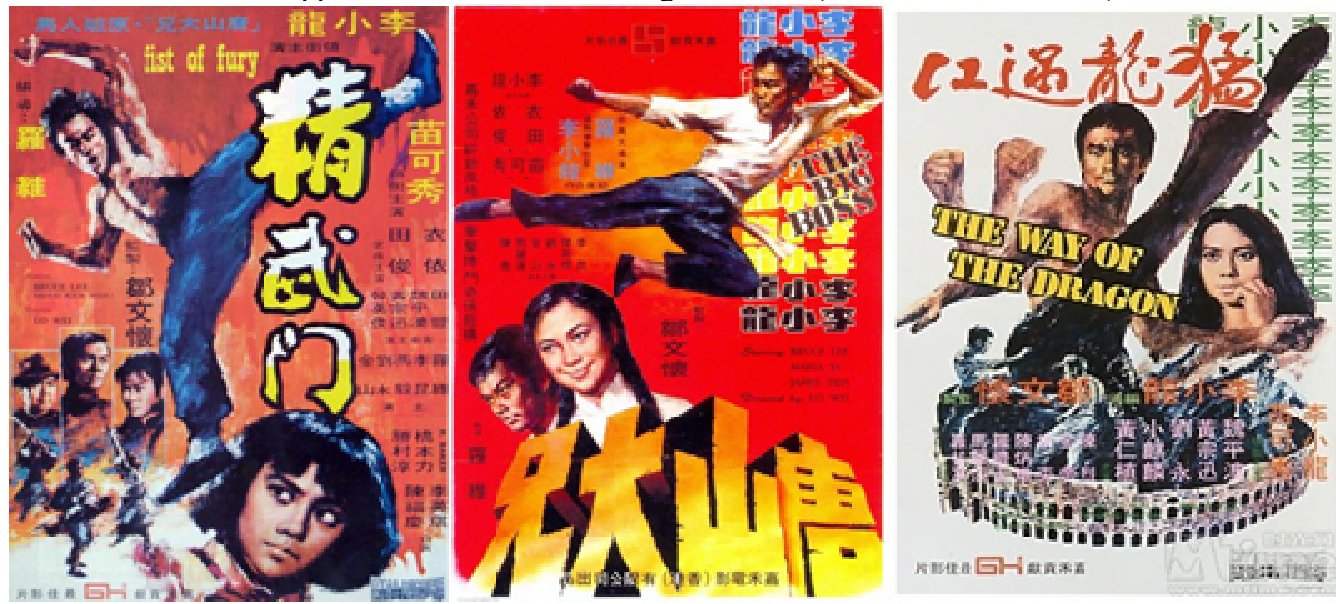

Figure 1. Hong-Kong made Bruce Lee's movies that pioneered the internalization of Chinese Kungfu. 
Till today, Bruce Lee's movies still get attention on the African continent. But it is important to mentioned that, another important legacy left by Bruce was the Kungfu Style and philosophy he created. In fact, the true reason that propelled him into the movie industry was the promotion of his martial arts theories and practices, and he did manage to do it well through mass media. Kungfu was his life, and he was driven by the idea of simplifying the world martial arts into one single and simple way: Jeet Kune Do. The idea of Jeet Kune Do was based on the traditional Chinese Wushu philosophy and techniques, but also contained the quintessence of other martial styles like the western boxing, karate, judo, taekwondo, fencing, Muay Thai, etc. At the same time, Bruce Lee's Jeet Kune Do kept a certain distance and difference with the traditional Chinese Wushu in the sense that he abandoned the "traditional routines" (套路) and focus on combat skills. According to Lee himself, "Jeet Dune Do is a simple truth: if the enemy does not move, I will not move. If the enemy wants to move, I'll move first.... Under certain conditions, biting the enemy with one's teeth can be regarded as an authentic method of Jeet Kune Do." (Zhang Xiaodong 2011) His best-known weapon was nunchakus that he promoted through his movies. Bruce Lee is the pioneer of making significant contribution on the popularization of Chinese martial arts in the west and in Africa trough his movies and the first to had resumed it in a single word "Kungfu" well known today in world dictionaries.

\subsubsection{The Jackie Chan Stage}

After Bruce lee, Jackie Chan became another emblematic figure of Chinese Kungfu in Africa. Robert Clouse the director of Bruce Lee's movie <Enter the Dragon (1973)> once compared both actors as follow: "In many ways, Jackie Chan is a great actor. He is a very good acrobat and martial arts master. Besides, he can handle humor with great mastery. On screen, he looks very much like a funny guy. He's not as tough as Bruce lee (Shu Yuan 2005)." In the late 1970s, Jackie Chan's Kungfu movie <Drunken Master (1978)> made the world fans of Chinese Kungfu rediscover another new way of playing Kungfu. It was during the Jackie Chan era that the comic martial arts style took place and progressively developed a new school of Kungfu fans in Africa. He combined action, comedy and pleomorphism, so created another breakthrough in the history of Chinese Kungfu film. Jackie Chan's Kungfu movies were even more closely related to Africa than Bruce lee's ones, not just in the screening stage, but from the shooting stage. In fact, movies such as $\langle$ Operation Condor (1991) $\rangle$, $<$ Who Am $I(1998)>$ were shot directly in Africa with a storyline involving African people, therefore more appealing to the African audience. The plot of $<$ Who Am I (1998) > for example is about scientific discovery in the African continent of a mysterious mineral with strong lethality. In a secret mission of exploring the mineral, the Central Intelligence Agency (CIA) secretly sent special forces to hijack scientists and their discovery, blackmailed by some powerful individuals pursuing selfish interests, the CIA special forces are all killed, only Jack (Jacky Chan's character) survived miraculously. Jack is saved by local indigenous tribe of South Africa. However, Jack has lost his memory and cannot remember his name, he keeps answering "who am I" to local indigenous who asked to know his name. The main scenes of the movie are played in South Africa. Breathtaking fighting scenes and high level Kungfu melt with comedy are displayed on the top of South African skyscrapers.

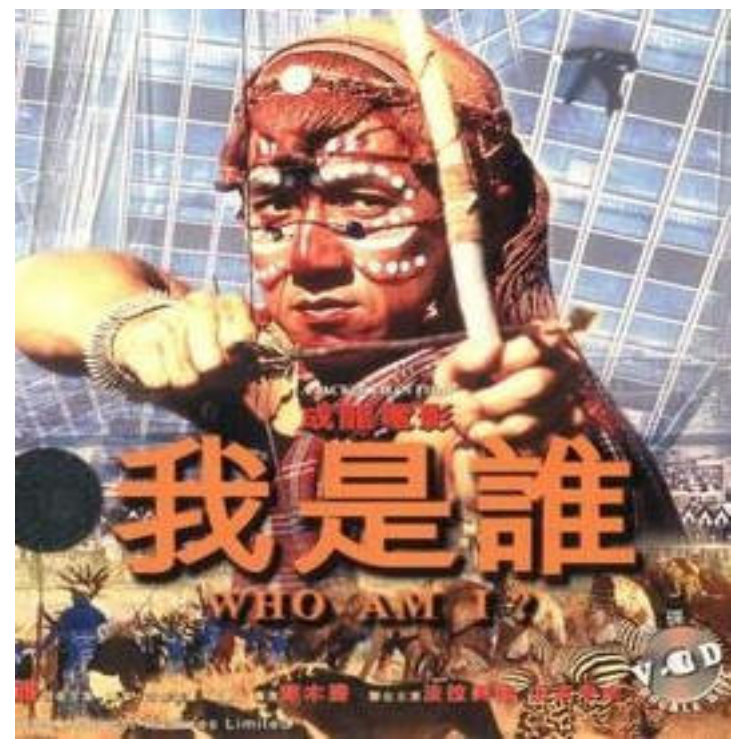

Figure 2. Jacky Chan's Movie < who am I (1998)> brought the Chinse Kungfu Closer to the African audience 
In short, Jackie Chan's Kungfu is no longer a thousand miles away story, but a Kungfu that belongs to the daily life of African audience. Jacky Chan is still very popular in Africa and remains an icon of Chinese Kungfu for thousands of fans and practitioners.

\subsubsection{The Jet Li Stage}

From the late 1980s to the 1990s, Jet Li made a name for himself in Africa through two main Kungfu Movies: $<$ Shaolin Temple (1982)> and <Taichi Master (1993)>. These two particular movies explore and exhibit in detail the close relationship between the Chinese Kungfu and dominant religious beliefs in China such as Taoism, Buddhism and Confucianism. The Chinese journal "People's Daily" overseas edition reported on the movie $<$ Shaolin Temple (1982)> as follow: "Jet Li has popularized the Shaolin temple all over the globe (Chen 2009)". Africa is a continent of strong religious beliefs, ranking from Christianity, Islam to various local religious beliefs, such as Voodoo, Totemism, Animism... as well as the worship of supreme God Yahweh. These religious beliefs share some common values with philosophical concepts preached in Shaolin Kungfu such as: "all beings are equal", "There's reward for good and punishment for evil", "the spirit is pure, but the flesh is weak" etc., from this perspective, African audience can understand better why monks in Shaolin Kungfu movies care so much about nature, life and justice. Kungfu is a tool for monks to purify the body and harmonized it with the spirit. For the Shaolin monks, Kungfu should be practiced in order to restore justice, protect the weak, love life, not to dominate others. And this is precisely the foundation of the "martial virtue (武德)" advocated by the Confucianism. Jet Li's movie <Tai-Chi Master (1993)> for example focuses on the long-term practice of ancient Chinese martial artists inspired by the "Yin-Yang" principle. Combined with the philosophical theory of Yin-Yang, the Chinese martial arts are more like a realistic carrier of Chinese philosophy taught to the world through movies. The word Tai-Chi for example was first used in $<$ The Book of Changes $>$, well known in China as <TAO TE CHING> (道德经), book about magical changes happening in the universe from which everything must had originated. The book says: "I (the TAO) has Tai-Chi, which gives birth to two states. Two states then developed into four images, and the four images gave rise to eight hexagrams, the hexagrams developed everything in the universe". "Tao (literally understood as The Way)" reveals the truth of the world, the origin of everything. "The self-governing rule of things in nature" is a guiding principle in Taoism (for example material things fall from top to bottom, water flows from up to down, etc. every single thing in the universe has a selfgoverning rule, including the people and their behaviors, that self-governing rule is the path to the truth, but is sometimes ignored or violated by the selfishness and greediness of humans). This doctrine is well conveyed in movies such as <Tai-Chi Master (1993) > and several others that fall in the same category, and Jet Li is the main contributor in popularizing this aspect of Chinese Kungfu in Africa.

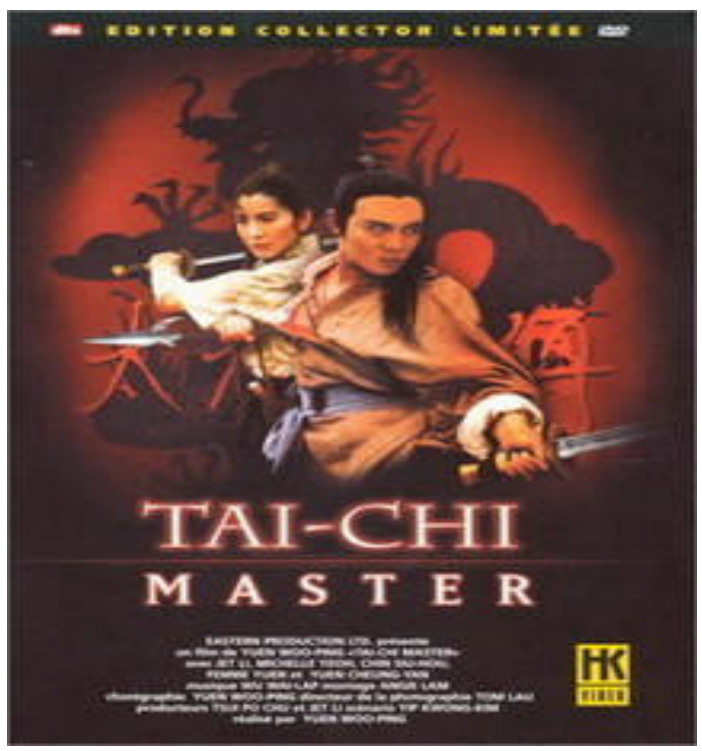

Figure 3. Jet Li's Movie <TAI-CHI MASTER (1993)> has popularized Chinese philosophy such as Taoism, Confucianism in Africa.

In 1997, Jet Li started a career in Hollywood and brought the Chinese Kungfu in western context with movies such as $<$ Romeo must Die $>$, $<$ Kiss of the Dragon $>,<$ The One $>$, etc. This has speed up the popularization of Chinese Kungfu and seduced even more young Africans fans. 


\subsubsection{The Donny Yen Stage}

Compared with Bruce lee, Jackie Chan and Jet Li, Donnie Yen is the latest Kungfu movies' star to propel the "Kungfu boom" among young African audience to a new stage, mostly due to the fact that he has arrived at a high stage of information technology revolution in Africa. In fact, Africa has known an internet boom in the late 1990's to the 2000's. In 1996 for example, the African Information Society Initiative (AISI), an action framework to build Africa's information and communication infrastructure stated that : "We have missed the industrial revolution, but we can no longer miss the information technology revolution (Feng Xue 2006)." The quick development of Internet has accelerated the spread of Chinese martial arts in Africa in the 2000's. With the youngest population in the world, Africa's movie goers are younger and younger. From 2000 up to now, Donnie Yen has been popular in Africa mainly through his IP Man series of movies: namely <IP Man $1(2008)>$, <IP Man 2 (2010)>, <IP Man 3 (2015)> and perhaps <IP Man 4> that is projected for 2020. Through the IP Man Kungfu movies' series, Donnie Yen introduced the legendary Kungfu grandmaster "IP Man" with its philosophy of “Benevolence(仁慈)”, a Confucian philosophy embodied in IP Man's character. For the Chinese philosopher Confucius, the benevolent is invincible(仁者无敌). No enemy or opponent or adversary could resist the benevolent, for the probity and kindheartedness elevate Man above others (Chen 2002). Another reason for the IP Man's series to be very popular in Africa is that the legendary grandmaster IP Man is well-known to be Bruce Lee's master. Moreover, <IP Man 3 (2015)> in particular show up a wonderful fighting scene opposing IP Man versus the legendary African American Champion boxer Mike Tyson. For the world audience, this is more than a movie. It is East versus West, a confrontational fight opposing the Chinese Kungfu to the western boxing, a three minutes challenge that has particularly drawn the attention of African and African American fans of Chinese Kungfu.

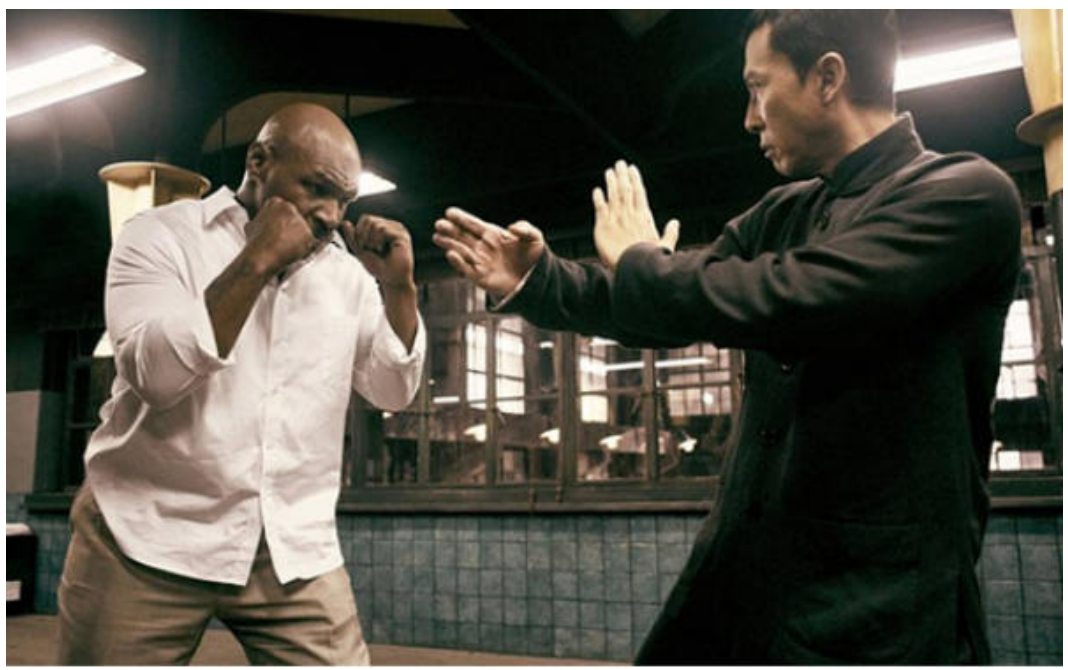

Figure 4. Wonderful fighting scene opposing IP Man (Donny Yen's character) VS Mr. Frankie (Mike Tyson's Character) in $<I P$ Man 3 (2015)>

Donnie Yen just as his predecessors Bruce lee, Jackie Chan and Jet Li, ended up with a career in Hollywood, using a much more international platform to reach a wider audience, making the Chinese Kungfu becomes a global phenomenon.

\subsection{Chinese Martial Arts Communication in Africa through People-to-people Exchanges: Case of Cameroon} Africa is a huge continent of 54 countries, it wouldn't have been possible to realize the fieldwork in the whole continent given the limitation in time and resources. Moreover, for geographical and historical reasons, we restricted and focused our study in Cameroon ${ }^{1}$. The people-to-people exchanges starts with the establishment of diplomatic relations between countries. Since the establishment of diplomatic relations between China and Cameroon in 1971, both countries have enjoyed close friendship ties. Cameroon is one of the earliest African country where the Chinese martial arts got to enter Africa and began to develop, it is also a country with remarkable cultural diversity and dense traditional martial arts culture, well-known as "Africa in miniature". Therefore, is of great theoretical and practical significance for the understanding of Chinese martial arts in Africa

\footnotetext{
${ }^{1}$ From June 10 to August 30, 2019 the Author conducted a field work in Cameroon, including interviews and participant observation.
} 
and Cameroonian martial arts could be a representative example of African martial arts in our study. Earlier studies show that, the earliest stage of Chinese martial arts practices in Africa is traced back to the 1980 (Nguema Akwe 2011), and the traditional martial arts such as Shaolin Wushu were the main contain. But in the case of Cameroon, the practice of Chinese martial arts was pioneered even before the establishment of diplomatic relations between China and Cameroon. Oral history conducted by the author in Cameroon reveals that, in 1969, “Huang-Ning(黄宁)", a Vietnamese Kungfu master on business trip in the Cameroon economic city Douala performed for the first time the Chinese Kungfu in Cameroon, and that was probably the first Kungfu performance in sub-Saharan Africa. On April 4, 1969, at the invitation of the Yaoundé Christian church, master "Huang-Ning(黄宁)" performed for the first time in the capital City of Cameroon in front of many Cameroonians, the content of his performance included the Chinese “Qigong gravel(气功碎石)”, “grapplingsparring(擒拿)" and “Sanshou-Combat (散手搏击)". But because of his short stay in Cameroon, he did not properly transmit his Chinese martial knowledge to the locals. It is only in the 1980's that the Cameroonian master Jean Jacques who had stayed in France for several years and learned the Chinese Shaolin Kungfu from a Chinese Master living there, returned in Yaounde the Capital city of Cameroon in 1985 and established the "Tran School of Martial Arts" where he taught the Chinese Kungfu to Cameroonians for several years. Few years later, many Chinese workers arrived in Africa and introduce the Chinese martial arts during their stay in Cameroon. Among them was the grandmaster Di Guoyong, one of the earliest high-profile Chinese Kungfu master to teach Kungfu in Cameroon. This well-known figure in the Chinese martial arts circles was invited in Cameroon under a construction project and stayed from 1988 to 1989 (ChinAfrica vol.3 September 2011). According to Master Di himself: "at that time there was only one Chinese cook who knew some martial arts, and he himself admitted that he was an amateur. I was the first high profile to introduce the Chinese martial arts to that country. I taught at the club Kamikaze and I decided to divide the course into three classes: Shaolin boxing for children and adolescents, self-defense for adults, and Tai-Chi for older people. My students were practicing very seriously. They were very good at sports in Cameroon." In a word, through people-to-people exchanges, the practice of Chinese martial arts in Africa was effective and the Chinese Kungfu went from screen to real life practices and experience. This was the join efforts of both Cameroonian masters who had studied Chinese Kungfu abroad, and the Chinese masters who went to Africa through various development projects and transfer their martial knowledge and skills during their stay.

\section{Influence and Changes of Chinese Martial Arts in Africa}

One of the fundamental goals of intercultural Communication is to narrow the "Cultural gap" between the people involved in the communication. However, in its dissemination process in Africa, the Chinese martial arts have been influenced by several factors that have led to its "misinterpretation". Thus, creating a "cultural gap" between the transmitter and the receiver, and so resulting to a "new understanding" of Chinese martial arts in Africa. Among those influential factors, the most noticeable are: the "communication carrier", the "language barrier" and the "receiver's cultural background". They have played a significant role in the "new understanding" of Chinese martial arts on the African soil.

\subsection{The "Communication Carrier"}

\subsection{1 "Movie" as Carrier of Chinese Kungfu}

From the perspective of communication studies, a "carrier" is the medium that carries information in the process of information transmission. The Information Technology revolution is in a certain extent, the revolution of the information carrier. From CD, DVD to Cinemas and Internet, the ways movies carry the information have ever since being upgraded. It is well known that movies have been the most influential carrier of Chinese Kungfu around the globe. However, by questioning ourselves on "Chinese Kungfu" as shown in movies and the Chinese martial arts as practiced in real life and often referred by the Chinese themselves as "Chinese Wushu", it is obvious to realize the divergence between both concepts. Movie is a sort of modern art that takes modern scientific and technological achievements as means of creating visual images and lens combination to shape the specific image of movement, sound and painting combination and lifelike in the space and time of the screen, so as to reflect social life. Movie can accurately "restore" the real world (case of documentary movie), but can also "distort" or "twist" the reality, creating a virtual world based on pure imagination. To a certain extent, movie can use montage, special effects and other artistic breakthrough of the film art to create a virtual reality that fit our minds and expectations but estrange us from our daily reality. And this is verifiable in many Chinese Kungfu movies. Although the Chinese martial arts can provide advanced practitioners with wonderful artistic skills and a considerable lethal force in real combat, but not to the degree of "flying", "fighting hundreds of opponents at once" or "hurt with a drop of water" etc. as it is the case in most Chinese movies. In Jet Li's Kungfu movies for example, it is most likely to find such "invincible Kungfu masters" with marvelous fighting skills, displaying a kind of aesthetic martial arts dream, that unfortunately have less to do with the "Chinese Wushu" (Jet Li's movies such as $<$ Evil Cult $>,<$ Hero $>$, etc. are illustrative examples). This may be source of curiosity for African 
audience, especially those who have never practiced the Chinese martial arts in real life, or those that do not understand the tricks behind the movie. Some African Kungfu movies goers under the impulsion of these visual contents, have pathed their ways to China in order to discover the reality behind the scenes, while others have been misled to believe that "Kungfu" can grant superpowers like in fiction movies. In fact, the Chinese Kungfu as displayed in such movies has given rise to skeptical views about the Chinese martial arts, to such an extent that many foreigners still sincerely believe that highly initiated Shaolin monks or example can "fly". That attitude was noticed for example in Luc Benza, an African fan of Kungfu movie who left his homeland Gabon since he was 14 years old and found his way to China in hope to meet with the "flying Chinese". with the help of his uncle, Benza later assisted to a Kungfu movie shooting scene in Beijing and was really disappointed by all the ingenuity and art work that were ongoing behind the scene to provide actors with "flying skills". "Since then, I understood that everything was fake", said Benza in an interview with Zhang Yong (Zhang Yong 2016). However, he did not give up with his passion for Kungfu movies and later became himself an African Kungfu movie star. The Cameroonian Dominique Saatenang as well after watching a Bruce Lee's movie, resolutely set his mind to become the African Bruce Lee and later became the first African monk after 4 years of hard training and initiation at Songshan Shaolin Temple in China. "One night, when staring at Bruce lee's movie $<$ Enter the Dragon $>$, my worldview suddenly changed. I made the important decision to practice Chinese martial arts to be like my idol Bruce Lee. I was only 11 years old and my parents rejected the idea, proposing better options such as foot-ball that is very popular in Cameroon. I have persevered with my choice and have become the first foreigner to be officially accepted and professionally trained by the Chinese monks. I am the first African monk and have been entitled ambassador of the Shaolin temple to the world", revealed dominique in an interview with the author (Taling).

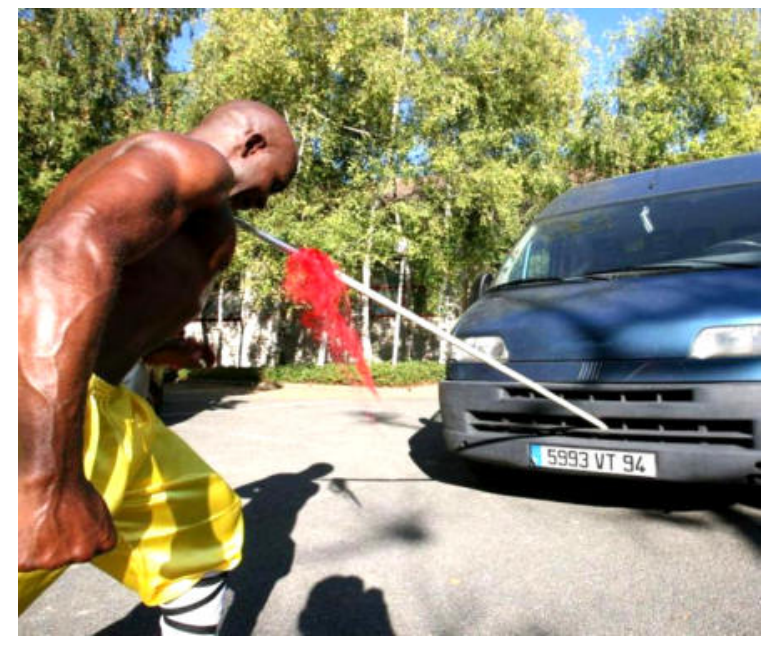

Figure 5. The African Bruce Lee Dominique Saatenang in a hard Qigong performance

We can name many examples like these ones. The point here is that the distance between the "exaggerated" and "unrealistic" cinematic "Chinese Kungfu" displayed in Kungfu movies, and the authentic Chinese Wushu as practiced by Chinese ancestors in the course of history is as wide as the existing gap between the African understanding, thus the "new-understanding" of Chinese Kungfu and the Knowledge package embodied in the Chinese Wushu.

3.1.2 "Body" as Carrier of Chinese Kungfu

As the communication between China and African countries is increasing, people's flow between both sides is increasing as well. Studies show that at the beginning of 1950, there were only 50,000 Chinese in Africa. Later after 1990, they were a massive Chinese migration in Africa, and at around the year 2000, the number of Chinese in Africa was estimated to be up to 1 million people (Li Anshan 2000). Even though they come for diverse reasons such as business, constructions and many other development projects, some among them have got a deep knowledge of martial arts and have become important carriers of Chinese Wushu in Africa. As a sort of body culture, Wushu in real life has spread through sports training in practice. The body as carrier of culture will inevitably affect the cultural transmission Wushu skills. The body of the martial artist is the carrier of martial arts skills, both (the body and the martial skills) are integrated into one and become the "martial body". The newunderstanding of Chinese "Wushu" will then be conditioned by the "martial body". however, Chinese and African have huge differences when it comes to body features. The concept of "body" in traditional African 
sport culture has important cultural connotation and social significance. People with big and powerful muscles will inspired respect and recognition from others, while those with thin muscles may be looked down upon. In the modern African sports culture as well, is well known from boxing to wrestling, from basketball to track and field etc. that the African body inspired respect and acknowledgement, for it is powerful and muscled, and when well-trained may deliver the best performance. In the basis of this reality, the African learner of Chinese Wushu will appreciate or depreciate the Chinese master. African practitioners will inevitably take their knowledge system of body concept to explore the cultural information conveyed by the body of the Wushu master. We remember for example that Bruce Lee himself just as many Chinese of his time in the United States, was sometime labeled as "sick man of east Asia(东亚病夫)". We see him in his movie <First of Fury $>$ breaking furiously a wooden board with that inscription "sick man of east Asia". The same scenario is repeated in Jet Li's movie $<$ Body Guard $>$. On the one hand, it was racist against Chinese people who stood up against Japanese and Western imperialism, but on the other hand, it is reflective of the physical difference between the body features of the Chinese and Western people. Until Bruce was able to fight in all occasion to prove himself, nobody would believe that behind the tiny body of Bruce lee lies a legendary grandmaster of all the time. This is true in the African body's culture where the physical appearance has a strong social significance. As immediate consequence, the learner will tend to look down upon or discredit the teacher until the latter prove himself competent though a singular combat. This is an obstacle to the martial arts transmission.

\subsection{The "Language Barrier"}

According to the Sapir-Whorf hypothesis: "Language influences and even determines the thinking" (Richard Palmer 1969). Cross-culturally sensitive fans of Kungfu for example, are aware of Bruce Lee's English nickname, "Dragon". In Christian Africa for example, the term "Dragon" refers to an animal with a negative connotation both figuratively and culturally. It is also referring to a biblical beast or monster. This is quite opposite to the Chinese cultural meaning of dragon that was embodied in Bruce Lee's Nickname. This could be misleading for that particular audience. In addition, the Chinese Wushu as intangible part of the Chinese culture, is closely connected to the Chinese language, so that the knowledge of the Chinese language becomes an imperative to deepen the knowledge of Chinese Culture. On the other hand, the receiver will have a better access to the information if he or she gets that information in his first language. This seems somehow paradoxal given the unpopularity of the Chinese language on the African continent and the lack of African languages versions of Chinese Kungfu movies, especially those of the 1970s, 1980s and 1990s. As a consequence, most African audience were often drawn to watch fighting scenes without understanding the reasons why all these fights were going on as some on those movies were broadcast in Chinese language. Even today with the translated versions, there are language differences and translation errors, especially in a place with more than 3,000 languages, such as Africa (According to the UNESCO (Shu Yunguo 2012)). In fact, earlier in 1813, the German translator Schreier Marcher put forward in his book on <The Method of Translation> that: "there are only two ways of translating: the translator can either keep the reader close to the author without disturbing the author, or keep the author close to the reader without disturbing the reader"( Schleiermacher \& Friedrich 1978). In 1995, Lawrence Venuti, an American translation theorist, gave named these two methods in his book $<$ The Translator's Invisibility >: the "domesticated" and the "Naturalized" methods. The "domesticated" translation refers to the maximum use of acceptable expressions based on the culture of the target language. The "Naturalized" translation however can make the translation natural, idiomatic, fluent but may not be easily accessible by readers of the target language. (Venuti 1995). Nida believes that in the process of translation, the translator should respect the characteristics of the target language and try to use the language forms that are acceptable to the receivers of the target language and conform to the target language expression norms (Nida 1993). In a word, neither "domestication" nor "Neutralization" can fully convey the original intention through translated works. Consequently, the audience will be unable to appreciate the wushu's philosophy conveyed by the language expressions in the movies. Similarly, the Chinese Wushu master in Africa will be teaching in his second language to non-Chinese speakers. Not only the teacher will be unable to fully express his knowledge or thoughts through the language, but the students understanding will be also limited by the lack of the cultural context of the knowledge transmitted as well as the restriction due to the knowledge acquisition through a second language. When teaching in Cameroon, Master Di Guoyong for example met with those challenges and expressed them as follow: "At first there was an interpreter who accompanied me all the time, then I started to learn some French for my classes.... The Chinese Wushu it's not just sport. Behind the physical practice, there is a system of thought about human beings that is directly inherited from Chinese philosophy and traditional Chinese medicine. This, the system, is also sometimes a barrier to the teaching, because not everyone studies what is inside the moves" (China and Africa, 2011). In brief, through movies or body practices, African receivers can only "get closer" to the cultural information embodied in Chinese Wushu. Strictly speaking, language is an inevitable obstacle between communicators and receivers. 


\subsection{The Receiver's Cultural Background}

The Chinese Wushu's content disseminated in Africa through people-to-people exchange can be divided into three main parts, namely, the "Sanda" or free combat (including real fight, traditional sanshou and self-defense techniques), "Taolu" or routines (barre hands, cold weapons, etc. ), and "Qigong" (method of boosting the body's internal energy through slow motion exercises, meditation, etc. so as to reach a more higher body potential and spiritual elevation with various benefits such as health preservation, powerful body expression, etc. ). Africa has a long-standing history of cultural development and martial arts practices. The African Martial Arts are an inalienable part of the African cultural identity with the unique feature of being grounded on the pursuit of body Combat through the powerful African body expression, while rooted in Spirituality (processes connecting the martial artist body to the spiritual realm), and fully expressed through the rhythmic and artistic beauty of the African Dance. The African Martial Arts as an intangible part of the African cultural heritage have since their formation, integrated "Combat+Spirituality+Dance" as core ingredients (Taling 2018); these ingredients are prerequisites for the African people to re-interpret similar phenomenon such as the Chinese martial arts and have somehow influenced the African understanding of the Chinese Wushu on the African soil.

\subsubsection{Interpreting the Chinese "Sanda" with the African body's Combat.}

From barbarism to civilization, each human society in their development processes, have naturally created series of fighting techniques and martial practices. Africa is known to be the cradle of earliest civilizations. Martial practices such as Engolo, Dambe, Laamb, Donga, Zulu Stick Fighting and so on, have a long-standing history and still exist in today's African societies, and together are constituencies of the larger family of African Martial Arts. These cultural patterns are reservoirs of African people's unique ways of living through space-time and are reflective of the connection between African people and their environment. Almost all African societies or ethnic groups have their proper term to describe what could be referred as martial arts or combats traditions, such as Nekang for the Bamileke people in Cameroon, Laamb for the Wolof people of Senegal, Umladlo Wezinduku of the Zulu people in South Africa, Mgba of the Igbo people in Nigeria, Messing for the Fang people of Gabon, Equatorial Guinea, Congo etc. In most African societies, people traditionally refer their "body combat" as "wrestling". But the concept of "wrestling" in Africa is very different from that in the West, Asia or elsewhere. According to the Nigerian scholar Svinth Abeegunde Balogun, "to wrestle an opponent" in traditional African martial arts means "to cause that opponent to fall on his back or his stomach using various unarmed (strike, sweep, kick, lock, push, etc.) or armed (stick, arrow, knife, stone, etc.) methods, making him vulnerable to a deadly attack." So, if you use a stick to knock over your opponent's head, by the standards of traditional African martial arts, you have wrestled your opponent (Balogun 2008). Through long-term development processes, African people have shaped their own systems of body's techniques based on their excellent physical condition. And this physical element make them more efficient when experiencing any other fighting system.

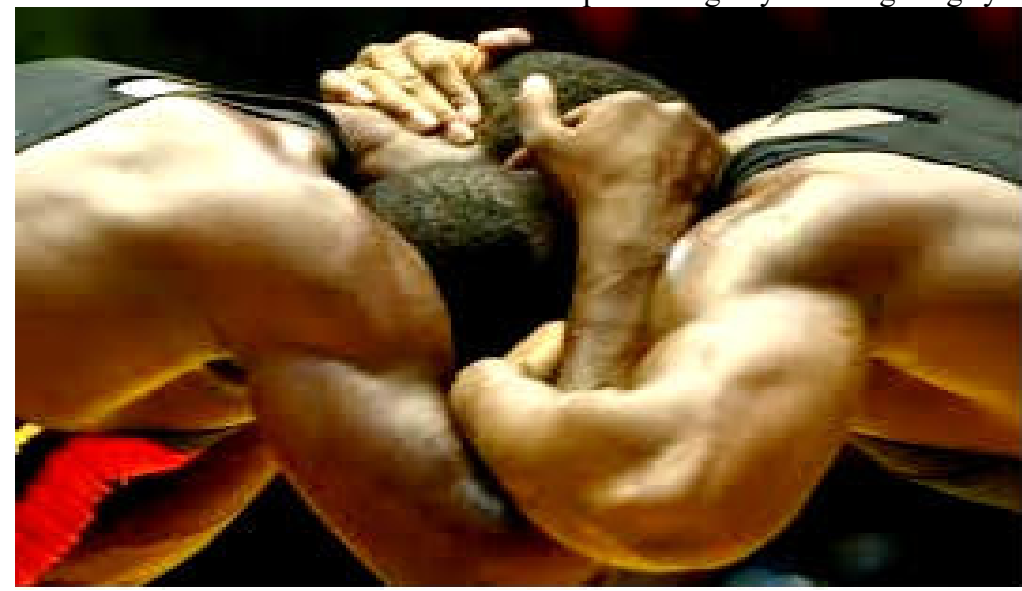

Figure 6. African Wrestlers Body' expression

African martial artists in general will approach other systems such as the Chinese martial arts with a comparative spirit. In some cases, African practitioners are often surprised when it comes to combative techniques sometimes displayed in traditional Chinese martial arts. The author in its field works have conducted an interview with $\mathrm{S}$. Merlin, a local law enforcement officer expert of combat, practicing both Chinese and Cameroonian martial styles. "We in the police are more interested in real combat, so our training system focuses on what is usable in real fight. From Kungfu movies one can say that, Chinese Kungfu is very efficient, but it raises curiosity as well. I later joined a Kungfu club to fill up that curiosity and verify what was usable. I have learned new stuffs there. Before, I wasn't used to fight using parts of my body like my fingers, or targeting parts of the opponent's body 
such as ears, or even bowing in very uncomfortable position to avoid an attack...these were very new to me. In addition, the movement of the steps and the principles of rhythm and breath in action are different from those I had previously associated with. These details, I can say, are my biggest gains. Chinese Kungfu also requires a lot of physical training, but I was not really impressed on this, because our traditional training styles since childhood include a variety of physical training methods sometimes even harder. I think the biggest difference between Chinese and African martial systems lies in the purpose we want to achieve. The Chinese Wushu preaches too much forbearance and mercy in combat, in addition they are many showy but unpractical moves. In my job I have to hit for real when it is needed and my code of conduct is guided by our local law enforcement policies." The Chinese scholar Hao Xiaogang while studying the African understanding of Chinese martial arts stated that: "It is not easy to understand the Chinese Wushu for many Africans who are used to fight each other to survive. ...Many people can't accurately understand the Chinese wushu culture when it advocates the "stop fighting" philosophy. They may fell confused and strange when they rely on their own cultural values to understand Chinese martial arts culture, and that will inevitably lead to the distortions of the Chinese wushu culture. Therefore, it may take time for Africans to understand the Chinese martial arts culture. (Hao Xiaogang 2007)"

\subsubsection{Interpreting the Chinese "Taolu" with the African Dance}

Africa is well known for its long-standing dance history; throughout time and evolution, the African combats traditions have been influenced by the rhythm, emotion and artistic beauty of the African dance. Some African fighting styles in time of peace have evolve into traditional folk dance as well. This has resulted to the formation of various African war dances and African martial arts routines. Some of these African "martial dances" are very popular in African societies and are inevitably the sets of knowledge foundation for African martial practitioners to understand and interpret the Chinese Martial arts routines (TAOLU). In the field work in Cameroon, the author has met with master Fabrice Mba, an African martial artist who is founder of a Cameroon Wushu association. As an advanced learner of Chinese martial arts and Champion of some Cameroonian martial styles such as the traditional wrestling, the "Sile Tia" etc. Master Mba have shared with us his understanding of Chinese Wushu through the African martial arts as follow: "I thought there was no connection between the world's martial arts, but the more I started practicing the Chinese Wushu, the more I realized that I was wrong. The Chinese Wushu have complex routines compare to those I have learned from Childhood in our local martial art 'Sile Tia', but the more I got familiar with the Chinese wushu, the more I felt it was similar to our Cameroonian martial arts. I've been practicing Shaolin Wushu for more than 20 years now, I went to China several times to dig down the roots of Chinese Wushu. I can say that in the process of learning Shaolin routines, many of the things I originally learned from our local martial arts are still repeated in front of me. Technically speaking, the basic skills are all the same."

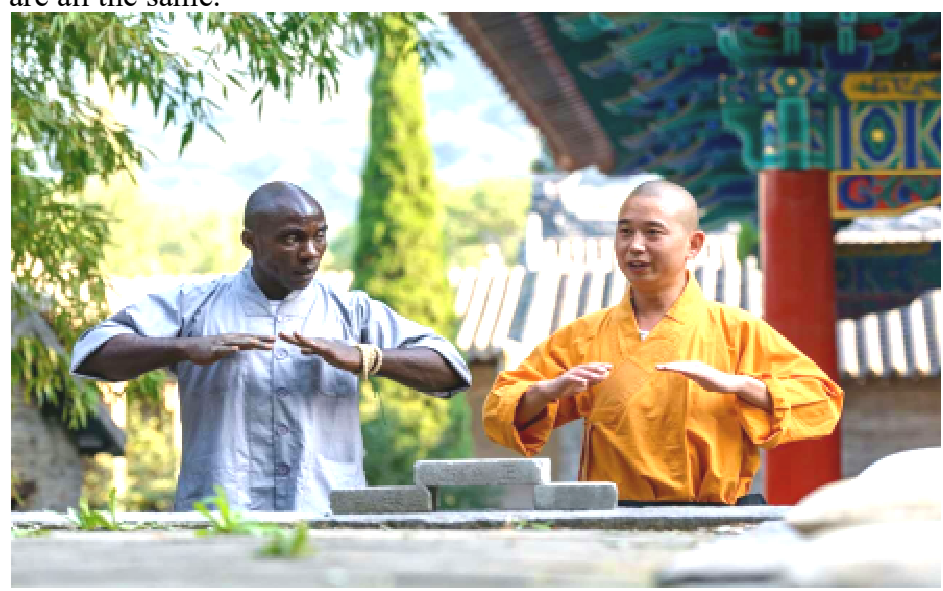

Figure 7. Master M. Fabrice training at the Shaolin Temple

"I have also discovered that, a Cameroonian traditional dance like Bikutsi (literally meaning trample the ground) which is based on the 'five steps', constitutes the foundation of those Wushu routines (Taolu). The major difference resides in our thinking and beliefs. In fact, the method that we use to trample the ground during our Bikutsi dance reveals our attachment to our deceased ancestors who bodies are buried under that ground. The reason why we "Trample the ground" is to let our underground ancestors know that we are still alive and strong than ever. Not only the steps should be applied in the right postures and must follow a certain rhythm, but they should be powerful enough, otherwise they won't be heard by the ancestors." The concept of "five steps" in Chinese Wushu, namely "Gongbu (bow step), Mabu (horse step), Pubu (servant step), Xubu (virtual step) and $X i e b u$ (rest step)" has a long historical and cultural connotation and is the milestone of the Taolu in the Chinese 
wushu, it reflects the Chinese people's unique understanding of their martial arts. The African concept of "five steps" in the Bikutsi dance for example expresses a different cultural reality, but somehow appears in the Chinese martial context expressing another cultural reality. And in conformity with the philosophical hermeneutics, one cannot totally get rid of its own cultural reality when experiencing a newest one, rather the "fusion of horizons" (Richard Palmer 1969) take place in such context. In a word, the Chinese Taolu can be imitated and repeated by African practitioners, but when it come to the culture embodied in the moves, the comprehension is different because influenced by the learners' cultural background and beliefs systems.

3.3.3 Interpreting the Chinese "Qigong" with the African Spirituality

When dealing with the spiritual world and the supernatural, the African traditional beliefs have shaped the spiritual component of the African martial arts, deeply rooted in various local rituals, initiations' ceremonies, etc. these spiritual elements have come to be the stone foundation for African martial artists to interpret the Chinese Qigong. In the Bantu culture (mainly among the Fang people present in countries such as Gabon, Cameroon, Nigeria, Equatorial Guinea, Congo, Central African Republic, etc.), "Eseneya” (this phenomenon can be named or represented differently in other African cultures or ethnic groups) is an essential part of the traditional African spirituality and a starting point for understanding foreign spiritual things. The Cameroonian scholar Philippe Laburthe-Tolra sees "Eseneya" or Esenga" as a union between a human being and other non-human consciousness through "Mebian", and the two will integrate into one single body (Laburthe-Tolra 1985). "Mebian" on the other side is explained by Mallart-Guimera as "Evu's demonstration of visible power (offensive and defensive), which manifests itself through the body of the initiate" (Mallart-Guimera 1981). " $E v u$ " finally is understood by Julien Bonhome as "the biological element that makes possible the alliance between a human being and a supernatural being" (Julien Bonhome 2005), it's a sort of seed in African spirituality. In some traditional African martial practices, "Evu" is the hyphen between the martial artist and it's "Eseneya" that is the incarnation or reservoir of his physical strength. But possessing an "Eseneya" involves a series of prohibitions that the martial artist should follow starting by a rigorous initiation process involving rituals and ceremonies generally performed under the guidance of a spiritual grandmaster "Gangha". Some previous studies have shown how these African martial practices influences the development of Chinese Wushu in Africa. In his book <Sorcellerie et Arts Martiaux en Afrique: Anthropologie des Sports de Combat >, the Gabonese scholar Olivier P. Nguema Akwe made a more advanced research on topic and show how African spirituality influences the practice of Chinese martial arts and in particular in the practice of "Chinese Qigong" in the central African country Gabon, here are some findings. According to the Author, the Shaolin Wushu came to Gabon in the early 1980's and incorporated local martial arts in its early development. Some of the earliest and most influential local master were known as master Lao-tse MVE Bertrand and master Jhon Lee Ondo. The two masters later develop the shaolin martial arts in the whole country. They founded and led the Chinese Wushu association and federation of Gabon. This is part of their interview conducted at Olumi Libreville by Olivier P. Nguema Akwe:

- Interview 1: A 69-years-old traditional shaolin Kungfu master named lao-tse MVE Bertrand from Gabon, Fang Ethnic group, head of the Gabon martial arts association, Interview recorded at 11:20 am on October 8, 2007 in Olumi Libreville by Olivier P. Nguema Akwe (P. Nguema Akwe, 2011:143-147). "As we all know, my great-grandfather was a great fighter, and starting from him our family has possessed the "Eseneya" of traditional wrestling, Eseneya is priceless to me. In Chinese martial art festivals, I repeatedly used "Eseneya" to achieved some hard Qigong performances, such as accurately cutting a papaya by the middle with a sharp machete while blindfolded and without hurting my disciple on whom the papaya was set, or breaking a $35 \mathrm{~mm}$ diameter steel bar with my neck (photo below). When I start entering in contact with my 'Eseneya' I am conscious, but once it takes control, what I do is unconscious and I am no longer the master of my (spiritual) body. I couldn't have completed such a performance without the power of 'Eseneya'. Can you imagine me bending $35 \mathrm{~mm}$ diameter straight steel with my neck? Normally That's not possible." 


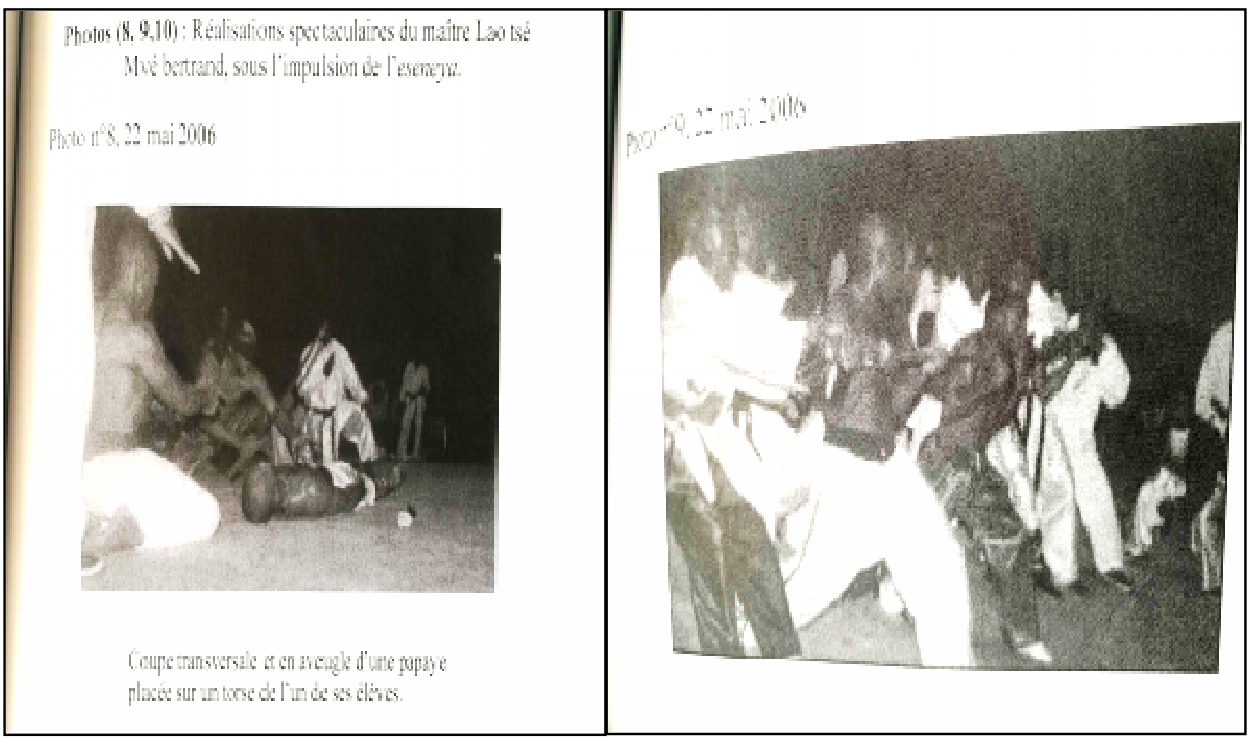

Figure 8. The master Lao-tse MVE Bertrand performing a difficult Qigong performance under the Control of Eseneya

“.... using the power of 'Eseneya' is not a simple thing, it requires advanced training, users must first learn to control it through a special initiation ceremony, most importantly, the user must be an advanced practitioner of martial arts, otherwise it will be very difficult to control it, 'Eseneya' is difficult to control in some situations and may take full control of the practitioner ( ... ) when I start the process, I fell very cold from inside, then progressively my body warms up, and I can feel the speed and power of my motions increasing. When the starting process is fully implemented, 'Eseneya' takes care of everything on my behalf (...) Look at the third photo (picture below), I am cutting a papaya placed on the neck of my female disciple. The process of the Qigong performance seemed so simple to me. I knew I was going to be successful because I knew I wasn't doing it alone. (...) The spectators were very excited by the show. Among the guests present that day were Chinese monks from China's Shaolin temple, they acknowledged the high-level performance and highly praised my martial skills."

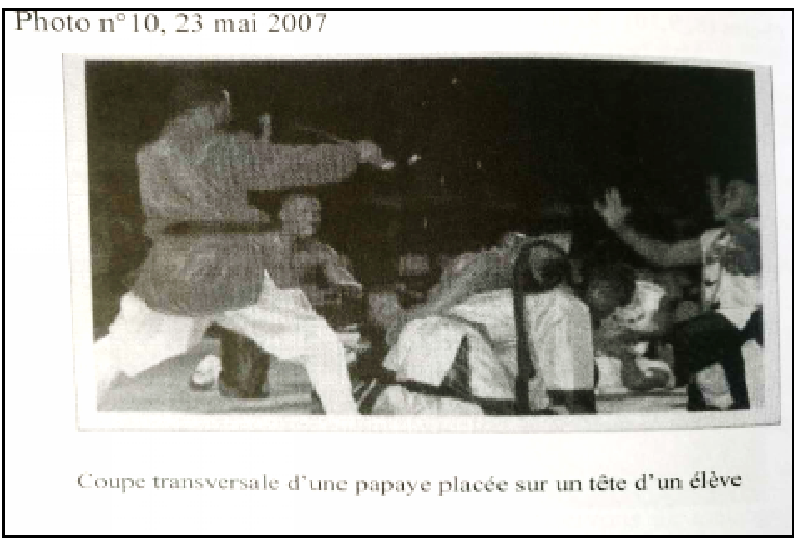

Figure 9. Lao-tse MVE Bertrand performing a difficult Qigong performance with the power of Eseneya

- Interview 2: A 59-year-old traditional shaolin Kungfu master named Jhon Lee Ondo, Fang ethnic group, head of the Gabon martial arts federation, recorded at 11:20 am on December 6, 2007, in Mindube Libreville by Olivier P. Nguema Akwe. (P. Nguema Akwe, 2011:143-176)

"I am a Kungfu master, and every great Kungfu master should have a secret, so I have mine, even if it's no longer a secret to everyone. 'Eseneya' is used by many athletes in Gabon, including footballers, so I'm not the only one. I'm just applying what I have learned. In many of my martial arts performances, especially that of last year, I used Eseneya's power to complete a template fragmentation. I used my head to break six thick boards at the same time. The crucial thing with "Eseneya" is the starting process..." 


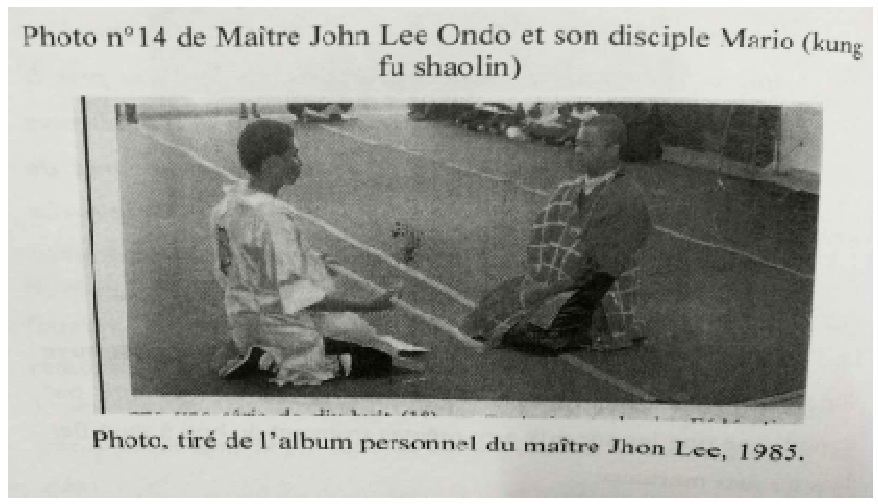

Figure 10. Master Jhon Lee Ondo (right on the picture) and his disciple

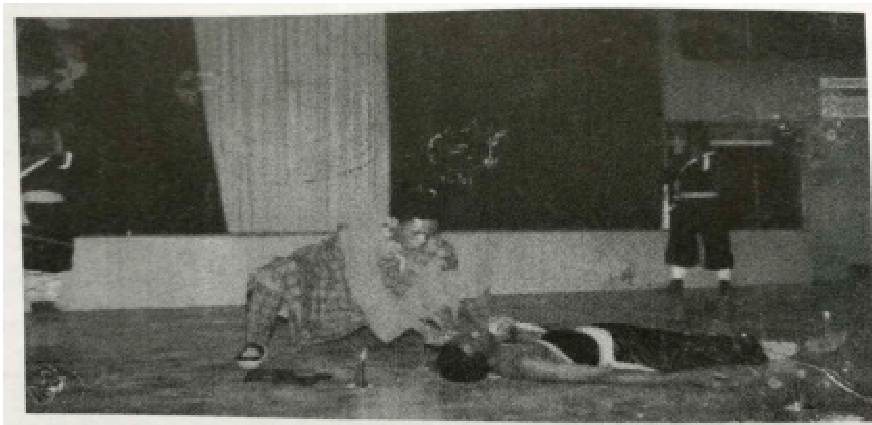

Tiré de l'album National de kung fu wu dang, 1992.

Figure 11. Qigong performance with the power of 'Eseneya'

The above interviews show that in traditional Fang culture, spirituality (simply understood here as the process of connecting the physical to the spiritual, or controlling the spiritual to influence the physical)" is the cornerstone of all complex or advanced human activities, especially activities involving the body, the mind and the spirit such as martial arts practices. And some spiritual entities like "Eseneya" provides the driving force that elevate the body to a supreme state where humans will then transcend their ordinary state to recover their original powers as granted by God. From this African point of view, the martial arts become a process of illumination where the practitioner through physical training and spiritual initiation seek to recover its true nature, a well-being state where he fully harmonizes with the universe through the connection created by his "Eseneya". This is why the Fang people regard "Eseneya" as the most fundamental element in their martial arts' conception. The Chinese Wushu as part of the large family of the world martial arts is no exception in the eyes of the Fang people. It is worth mentioning that, "Eseneya" is generally represented physically by animals such as panther, lion, gorilla, etc. or in some cases by a tree, or a rock... and that not everyone is eligible to possess an 'Esenaya'. One must have a pure, compatible spirit and most importantly noble intentions, mission or ambition as preconditions. However, some athletes or martial artists "non eligible" may get it through improper means, leading to the violation of traditional and natural processes, this can bring negative or even disastrous effects to the initiate, such as mental illness, madness or possession, and in some severe cases to the sudden death.

In China, the history of wushu development is also related to spiritual or religious practices, and the traditional Shaolin Wushu is a typical example of martial arts associated to religious practices (Buddhism and in some extend Taoism). Monks throughout long period of meditation and spiritual practices (prayers, poetical songs, incantations, rituals with candles light, etc.), will purify their physical body (already prepared by years of hard martial training) and elevate their spirits, seeking balance and harmony between the physical and the spiritual to restore the true nature of Man (Illumination). "Taolu” (Chinese Wushu's routines) for example can show the close relationship between human and nature, or more precisely between the Chinese people and their natural ecosystems. The Chinese Taolu reflects the imitation of nature by Man (Man copying animals' techniques and fighting styles such as the tiger style, the mantis style, the eagle style, the snake style...) and the strong desire of Man to harmonized with nature (through breathing, meditation as in soft-Qigong practices). African people guided by their philosophy and beliefs systems did not develop such a wide range of routines styles of Man imitating animals or natural phenomena in their martial practices, instead, they've focused on the supernatural 
dimension and borrowed the inherent power (spiritual) contained in animals, plants and other natural phenomena to fulfill their martial goals. As result, this has led to the African re-interpretation of Chinese wushu Qigong with the African spirituality in the process of intercultural communication between Chinese and African martial arts.

\section{Conclusion and Suggestions}

In this globalized world of the $21^{\text {st }}$ century, no culture is any more isolated from others. In its process of opening up, the Chinese culture has to interreact with different cultures. In this era of flourishing China-Africa relation, the need of mutual understanding is urgent than ever and this emergency is precisely a driver for both sides to speed up the intercultural communication. The popularity of Chinese Kungfu movies in Africa since the 1970's has set a basis for that intercultural communication and the establishment of diplomatic relation between new China and newly independent African states have provided a frame for the people-to-people exchanges, fueling up the cultural exchanges between China and Africa. However, the Chinese Kungfu as known from films has been "biased" and "distorted" by the unproper use of film media, and the unawareness of the cultural background of the receivers by the communicator has obstructed the information transmission, resulting to the "misinterpretation" of the Chinese martial arts and so creating a "cultural gap". The language barrier as well has undermined a proper transmission of the philosophical knowledge encoded in the martial arts. Through the people-to-people contacts, the Chinese martial arts communication in Africa has been achieved through physical practices of Wushu skills and routines. Through body practice and experience, the Chinese Kungfu was understood via the complex set of African martial arts, leading to the New-understandings of Chinese Wushu; in this process, the re-interpretation of Chinese martial arts took place and was rooted on "Combat, Dance, Spirituality" (Pre-understandings) embodied in the African martial arts, more precisely the use of traditional African body's culture to understand the Wushu's Combat (Sanda), the use of African martial "Dances" to interpret the Chinese Wushu's routines (Taolu), and the use of African martial arts spirituality to unscramble and explain the Chinese "Qigong”.

Based on the aforementioned findings, the present article suggests that, in the process of intercultural communication of Chinese martial arts in Africa, more attention should be paid on the interaction with local cultures, full play should be given to the receivers needs, their cultural background as well should be dig down (intercultural communication should be a two-sided activity in the sense that, we should make sure we understand those we expect to understand us), the communication canals such as movies should be handle properly (the stories and actions in Kungfu movies for example should be more closer to reality, special effects should not be exaggerated, etc.). This is beyond doubt the best way to speed up the rightful and global communication of the Chinese Wushu, as well as its local integration and the co-development with local martial arts, especially with regard to Africa where mutual understanding between Chinese and African people is strongly needed to support the win-win cooperation agenda of China and Africa. The eternal existence of "preunderstandings" leading necessarily to "new-understandings" in intercultural communication is a reminder that "localization" should be prioritized rather than "standardization", for without taking into account local parameters, the "internationalization" of cultures becomes a utopia.

* This research is funded by the "2019 Africa Research Project" of the Institute of African Studies at Zhejiang Normal University. Project No. FF201904. Project name: "Cultural Interaction Between Chinese Wushu and African Martial Arts”. Email: rodriguetaling@,outlook.com;

\section{References}

1- G. Hart (2005). The Routledge Dictionary of Egyptian Gods and Goddesses. Routledge Second edition, 158.

2- Francisco J. Gonzalez (2006). Dialectic and Dialogue in the Hermeneutics of Paul Ricouer and H.G. Gadamer. Continental Philosophy Review, 322-323.

3- Taling T. Rodrigue (2018). Deepening the China-Africa Cultural Understanding: Difference Between Chinese and African Martial Arts Conceptions. International Journal of African and Asian Studies, 12.

4- Taling T. Rodrigue, Yao Jiaojiao (2017). Kungfu Movies as Driver of China-Africa Cultural Exchanges: Case Study of Cameroon. International Journal of African and Asian Studies (36):45.

5- Zhang Yong (2016). African Film and TV Studies: A New Area of Chinese Academia. Zhejiang people's publishing house, 3-12.

6- David Murphy Sembene (2001). Imaging Alternatives in Film \& Fiction. First Africa World Press, Inc.Edetion, 98.

7- Zhang Xiaodong (2011). Study of Bruce Lee's Jeet Kune Do influence of the Chinese Wushu. Lantai World, 55 .

8- Shu Yuan (2005). Martial Arts Films in the American Context: from Bruce Lee to Jackie Chan. World Cinema, 12. 
9- Chen Zhenkai (2009). Witness the Era's Face: Sixty years of Literature and Art have blessed our Memories. People's Daily Overseas Edition, 07.

10- Feng Xue (2006). Listen to the Footsteps of Africa Catching up with the Information Age [Online] Available http://www.huaxia.com/zt/tbgz/06-057/2006/00529546.html (October 30, 2006).

11- Chen Pingyuan (2002). Ancient letters of Swordsmen dreams. Beijing: new world press, 232. (originating from the Chinese classic HANFEIZI: WUDU).

12- ChinAfrica (2011). "A Chinese Kungfu Master in Africa". Beijing Weekly newspaper, 54.

13- Zhang Yong (2016). African Film and TV Studies: A New Area of Chinese Academia. Zhejiang people's publishing house, 263-264.

14- Li Anshan (2000). The History of Overseas Chinese in Africa. China overseas Chinese press. Africa and China: More than minerals. The Economist. 23 March 2013.

15- Richard Palmer (1969). Hermeneutics: Interpretation Theory in Schleiermacher, Dilthey, Heidegger, and Gadamer. Evanston, IL: Northwestern University Press, 209.

16- Shu Yunguo (2012). Introduction to African History research. Peking University Press, 48.

17- Schleiermacher, Friedrich D (1978). E. The Hermeneutics: Outline of the 1819 Lectures. New Literary History, 1.

18- Gao Yang (2007). Domestication and Neutralization in the English subtitles' translation of Kungfu. Crazy English Teachers, 69.

19- Nida E. A. (1993). Language, Culture and Translation. Shanghai Foreign Language Education Press, 87.

20- Taling T. Rodrigue (2018). Deepening the China-Africa Cultural Understanding: Difference Between Chinese and African Martial Arts Conceptions. International Journal of African and Asian Studies (49), 11

21- Svinth Abeegunde Balogun (2008). Afrikan Martial Arts: Discovering the Warrior Within. Atlanta, GA: Boss Up, Inc.

22- Hao Xiaoguang (2007). Analysis on Conflict and Amalgamation of wushu culture Spread. Bulletin of Sports Science and Technology (01), 94-95.

23- Richard Palmer (1969). Hermeneutics: Interpretation Theory in Schleiermacher, Dilthey, Heidegger, and Gadamer. Evanston, IL: Northwestern University Press, 209.

24- Philippe Laburthe-Tolra (1985). Initiations et sociétés secrètes au Cameroun. Paris Karthala, 149.

25- Louis Mallart-Guimera (1981). Magie et Sorcellerie Evuzok. Paris Nanterre, Ecole de Hautes Etudes, 126.

26- Juliien Bonhome (2005). Le Miroir et le Crane, CNRS Paris, 154.

27- Olivier P. Nguema Akwe (2011). Sorcellerie et arts martiaux en Afrique: Anthropologie des sports de combat, L'Harmattan,143-147.

28- Olivier P. Nguema Akwe (2011). Sorcellerie et arts martiaux en Afrique: Anthropologie des sports de combat, L'Harmattan, 176. 